\title{
Teachers' Skills and Knowledge in Mathematics Education for Braille Readers
}

\author{
Annemiek van Leendert ${ }^{1}$ (D) - Michiel Doorman · Paul Drijvers · Johan Pel ${ }^{2}$. \\ Johannes van der Steen ${ }^{2}$
}

Accepted: 23 April 2021 / Published online: 6 May 2021

(c) The Author(s) 2021

\begin{abstract}
Braille readers use a braille display and text-to-speech synthesizer while reading and comprehending mathematical expressions and equations. Teachers need to have technological, pedagogical and content (TPACK) knowledge and skills for exploiting the potential of these devices in mathematics education. They have to understand how the use of assistive technology influences the teaching and learning of mathematics. Therefore, the aim of the current study is to support teachers to better understand the dynamic relation between the different TPACK domains. That is why a professional development course was developed in which five mathematics teachers of braille readers in special secondary education participated. The development of the teachers' TPACK knowledge was analyzed, and course characteristics that helped to develop this knowledge were identified. The results show an increased awareness of the importance of assistive devices, but only a small positive effect in TPACK knowledge and skills. Course activities related to the braille display, the mathematical braille notation and mathematical vocabulary helped to develop TPACK knowledge. However, course activities related to the text-to-speech synthesizer and working in heterogeneous groups did not work out so well. A better understanding of what teaching mathematics to braille readers means is expected to improve their learning.
\end{abstract}

Keywords Assistive technology · Braille readers - Mathematics education · Professional development course $\cdot$ TPACK

Annemiek van Leendert

A.J.M.vanLeendert@uu.nl

Michiel Doorman

m.doorman@uu.nl

Paul Drijvers

p.drijvers@uu.nl

Johan Pel

j.pel@erasmusmc.nl

Johannes van der Steen

j.vandersteen@erasmusmc.nl

1 Freudenthal Institute, Utrecht University, Princetonplein 5, Utrecht 3584 CC, The Netherlands

2 Erasmus University Medical Center, Rotterdam, The Netherlands 


\section{Introduction}

The importance of technology in mathematics education can hardly be overestimated. Various studies have shown that the strategic use of technological devices can support both the learning of mathematical procedures and skills and the development of advanced mathematical competences such as problem solving, reasoning and justifying (e.g., Gadanidis \& Geiger, 2010; Pierce \& Stacey, 2010; Roschelle et al., 2010). Although teachers generally appreciate the benefits of educational technologies, they often find smooth and effective integration of new educational technologies challenging. According to the so-called TPACK model, effective teaching with technology asks for a rich collection of knowledge and skills from teachers varying from technological (TK), pedagogical (PK) and content knowledge (CK) as well as an understanding of the interaction between these components (Koehler \& Mishra, 2008; Mishra \& Koehler, 2006). This interaction is constantly changing and, therefore, very complex.

The technology boom of the last decades has produced an abundance of devices to assist in learning and teaching, including those useful to teachers of students who are visually impaired (DePountis et al., 2015). The innovations in assistive technology support the accessibility of higher education and may serve as an equalizer in the lives of people with disabilities (Michaels \& McDermott, 2003), but also have an impact on the role and responsibilities of their teachers. Zhou et al. (2011) did a survey of 165 teachers of students with visual impairments to investigate their perceptions of their knowledge of assistive technology. The results showed, in particular, low ratings of the competences related to mathematics and science.

Although the importance of assistive technology for the success of students with visual impairments is no longer subject to debate, there remains a strong concern as to whether these students receive adequate instruction and training in this area (Pogrund \& Smith, 2012; Zhou et al., 2011). This is particularly the case for visually impaired students whose primary reading medium is braille (from here on braille readers). They need assistive devices, such as the braille display, tactile drawings, and tangible models, to get access to and explore mathematical representations. If we consider the teacher as the key to using assistive technology in mathematics lessons, then knowledge and skills described by the TPACK model should be considered important. The aim of this study, therefore, is to support teachers to better understand the dynamic relation between technological, pedagogical and content knowledge in mathematics education for braille readers. To investigate this, a professional development (PD) course for mathematics teachers of braille readers was developed.

\section{Theoretical Framework}

\subsection{The TPACK Model for Teachers' Competences}

Digital technologies gain interest in many educational contexts around the world (e.g., Mumtaz, 2000). The availability of these technologies challenges teachers' practices (Adler, 2000; Gueudet et al., 2012). The teachers' ability to use the opportunities offered by digital devices is a major determinant of the success of using these devices in mathematics education (Drijvers et al., 2013; Powers \& Blubaugh, 2005). 
Mishra and Koehler (2006) have developed the TPACK model that describes the knowledge and skills that teachers need to successfully integrate technology in their classroom practices (see Fig. 1). This conceptual model builds on Shulman's (1986) demarcation of the professional knowledge of teachers as pedagogical content knowledge (PCK). This knowledge is unique for teachers and distinguishes, for example, a mathematics teacher from a mathematician. Mishra and Koehler (2006) expanded this model with the addition of technological knowledge (TK). The TPACK model acknowledges the complex interaction between technology (TK), pedagogy (PK) and content (CK) knowledge (Mishra \& Koehler, 2006).

Although the TPACK model has been criticized for difficulties in distinguishing between the included constructs (Cox \& Graham, 2009; Graham, 2011; Voogt et al., 2013), the strength of the model is that it questions content-neutral or pedagogical-neutral teaching practices (Harris et al., 2009; Koehler et al., 2013). Specific technologies have their own potentials, affordances, and limitations that make them more suitable for certain tasks and pedagogies than others (Koehler \& Mishra, 2008). The use of the graphics calculator-in contrast to a calculator that does not display graphs-, for example, encourages the integration of geometric and algebraic activities (Drijvers \& Doorman, 1996). Understanding how the affordances and limitations of technologies affect what teachers do in their class is not easy and may necessitate rethinking teacher education and professional development. Teachers' knowledge, however, is not the only factor influencing their TPACK

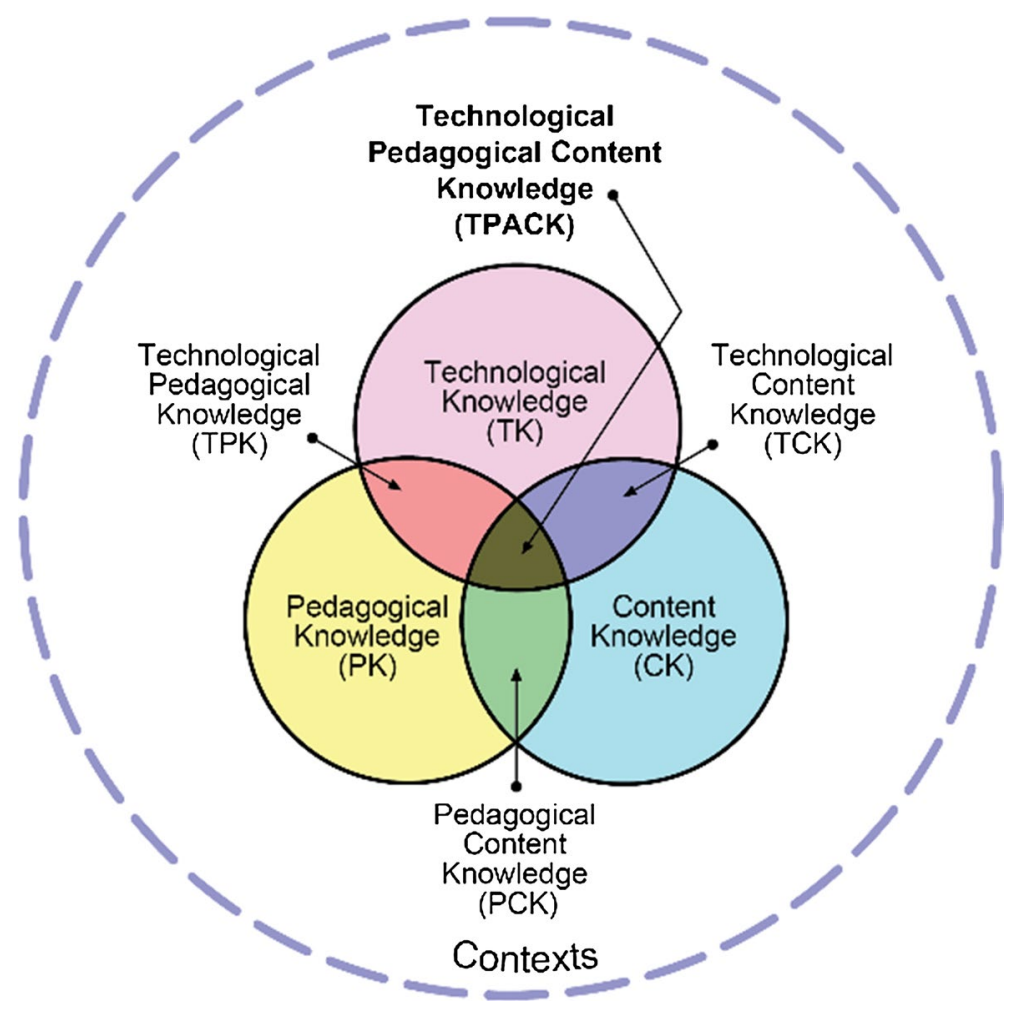

Fig. 1 The TPACK model. Retrieved from http://www.tpack.org/ 
construction. Contextual factors, such as the availability of technological support, school culture and teachers' perception of their responsibilities are influential factors as well (Koehler et al., 2013; Koh et al., 2014).

\subsubsection{The TPACK's T in Mathematics for Braille Readers}

In the current study, the T in TPACK stands for assistive technology that braille readers (have to) use to get access to mathematical representations and to communicate mathematically. Assistive technology refers to extra materials or time in addition to what "ordinary" students get, and to alternative materials (e.g., text in braille or tactile drawings) (Young \& MacCormack, 2018). In this study, the most important assistive devices are braille, the braille display, the text-to-speech synthesizer and the mathematical braille notation.

In the Netherlands, braille readers in secondary education use a laptop with screen reader software. A braille display is connected to the laptop. The screen reader software allows a braille reader to read the text that is displayed on the laptop screen with a braille display or text-to-speech (from here on TTS) synthesizer. The braille display enables a braille reader to read one line of text at a time. Text-to-speech synthesis is a technology that provides a means of transforming text from a descriptive form to spoken language. The TTS synthesizer can read a character, a word, a line or full text screen.

Braille readers and students who can see (hereafter called print readers) make different use of their senses to perceive mathematical expressions. Because braille readers lack visual input, they have to rely on assistive devices to access mathematical representations. They read mathematical expressions and equations in braille, either in coordination with speech synthesis or not. The perception based on touch or hearing is more serial than the parallel perception based on vision (Millar, 1994, 1997). With serial processing, it is more difficult to get an overview on formulas or equations (Van Leendert et al., 2019). In addition, braille characters have a low redundancy because they only differ from each other in the presence or absence of a dot in one of the six (or eight) possible locations (Millar, 1997; Tobin \& Hill, 2015). This low redundancy makes it challenging to discriminate between the characters. Compare, for instance, the braille characters $\because$ (m) and $\because$ : $(x)$. A third factor is the lack of contextual clues, like those experienced in non-mathematical text that may include familiar words and phrases. In summary, it is difficult to read mathematical expressions accurately in braille, because of the serial perception, the low redundancy and the lack of contextual clues.

The (formal) mathematical notation that print readers use contains many unfamiliar symbols and makes use of techniques such as arranging characters at different heights above or below the base line to convey structure (Stöger \& Miesenberger, 2015). Examples are the square root sign and the fraction notation (e.g., $\sqrt{ } 4$ and 1/4). These visual cues help print readers to understand the structure of an expression. Braille and speech, however, are linear output modalities. Therefore, an expression in the mathematical notation has to be transformed into an expression in a linear notation. Consider the expression $(x+2)^{2}$. When following the rules of a Dutch 8-dot braille notation, this expression needs to be transformed into the expression $(x+2)^{\wedge} 2$. We call this a linear-print expression, which stands between the representation in formal mathematical notation and the representation in braille. The screen reader software transforms this linear-print expression into a linear-braille expression (气。: There is a one-to-one correspondence between the ASCII characters in the linear-print 


\section{mathematical notation}

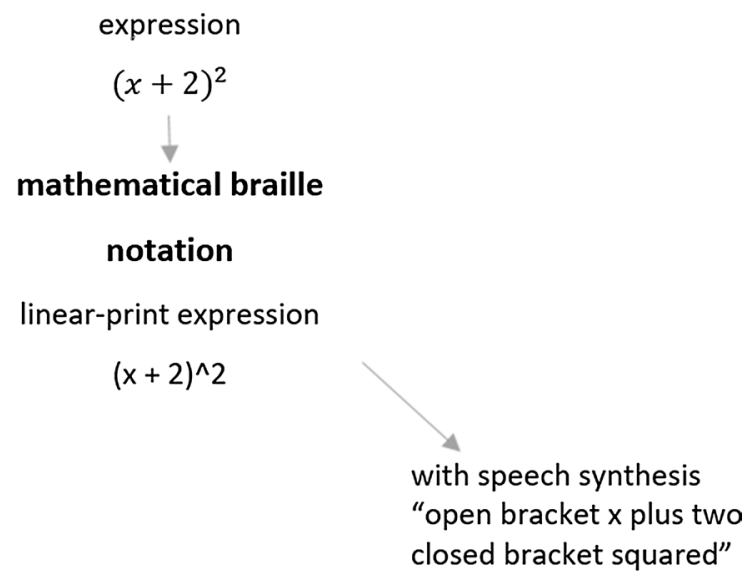

Fig. 2 Transformation of an expression into braille or speech synthesis. Note The mathematical braille notation used is a Dutch mathematical braille notation.

expression and the braille characters in the linear-braille expression. How the linear-print expression is pronounced depends on the settings of the screen reader software.

To perceive the linear-braille expressions through touch is challenging. It is very different from scanning mathematical expressions with the eyes. When one can use sight, one can get an overview of these expressions and, for instance, distinguish the difference between an equation and a formula within a split second. Braille readers use their fingertips while reading in braille. This reading is serial, because the fingertips must necessarily pass over all sequential braille characters on a line (Hughes, 2011; Pring, 1984). Hence, braille readers need to decode the braille characters and at the same time build an overview of the expression. When braille readers use a speech synthesizer, they must also build an overview. Speech synthesis provides less structural information than braille, because braille offers spatial information about the expression and allows for more control while scanning. An advantage of speech synthesis over braille is that it allows for a faster pace of reading.

In summary, the representation of expressions in braille or through speech synthesis is different from the representation in the mathematical notation seen through the eyes. In addition, tactile or audible perception is different from visual perception. Therefore, the use of braille or speech synthesis influences the way in which mathematical content is presented and can be manipulated, and they influence the teaching and learning of braille readers.

\subsubsection{The TPACK's P in Mathematics for Braille Readers}

The classes at schools for visually impaired students are often very heterogeneous (Baril, 2008). The students differ in visual ability, in academic ability and in their use of assistive devices. Teachers have to use assistive technology, such as the mathematical braille notation, tactile drawings and 3D models, to connect their teaching to the personal needs and preferences of their braille readers in order to enhance individual skills.

Another, more inclusive, approach is cooperative learning. In this approach, the emphasis is on creating opportunities for students to learn to collaborate and 
communicate mathematically, which is important for the overall development of their mathematical proficiency needed for participating in future work and society (Riccomini et al., 2015). A special form of cooperative learning in mathematics is inquiry based learning (IBL). This approach includes student-centered teaching strategies with a focus on processes of inquiry that include planning, collaborating and communicating. Mathematics teachers need to support these processes of inquiry with carefully designed tasks, structured lessons to ensure progress in the learning of knowledge and skills (Artigue \& Blomhøj, 2013). IBL is driven by open questions and multiple solution strategies, and teachers need pedagogical skills to have students' approaches formulated, compared, evaluated and discussed (Maass \& Doorman, 2013).

In summary, the $\mathrm{P}$ in TPACK includes skills to value and connect to individual students' preferences in reading and to communicate mathematically, as well as skills to organize inquiry in their classrooms.

\subsection{The TPACK Model for Mathematics Teachers of Braille Readers}

In this paper, TPACK is introduced as a conceptual model for the knowledge base that teachers need to effectively teach mathematics to braille readers. We interpret TK as knowledge about assistive devices such as the braille display and TTS synthesizer. Teachers need to be able to identify useful devices for braille readers and to be able to continually adapt to technical innovations. Technological Content Knowledge (TCK) is an understanding of how assistive devices and content influence and constrain each other, for example, understanding that it is difficult to get an overview of a mathematical expression while reading in braille. Technological Pedagogical Knowledge (TPK) is an understanding of how teaching and learning change when assistive devices are used. For instance, reading speed probably will decrease when a braille reader switches from reading with speech synthesis to reading in braille. Finally, Technological Pedagogical Content Knowledge (TPACK) is an understanding of how to represent and explain mathematical concepts to braille readers and the ability to use and select the best assistive devices for specific mathematical practices. For instance, the ability to use and select an audible graph when the braille reader needs to get a global overview of the relation between two variables and a tactile graph (or a table in braille) when more detailed information is needed. According to TPACK, the use of assistive devices is an integral tool for teaching mathematics to braille readers (Fig. 3).

We developed a TPACK-based course for mathematics teachers of braille readers with the aim to support them to better understand the dynamic relation between technological, pedagogical and content knowledge in mathematics education for braille readers. The design of the professional development (from here on PD) course was guided by different principles. First, the activities have a focus on content, pedagogy and technology closely linked to the practices of the teachers (Koehler et al., 2013; Koh et al., 2014). Second, the course activities are inquiry-based (Van Veen et al., 2010). An example of such activities are the IBL-activities (Swan et al., 2013). Third, in some of the activities, the instructor serves as a role model to illustrate expected teaching practice (Lunenberg et al., 2007). Fourth, the teachers actively construct knowledge and learn together during the course through small group activities (Van Veen et al., 2010). Fifth, the teachers get opportunities to try out in their practice (Guskey, 2002) and reflect on and discuss their experiences at follow up meetings. 


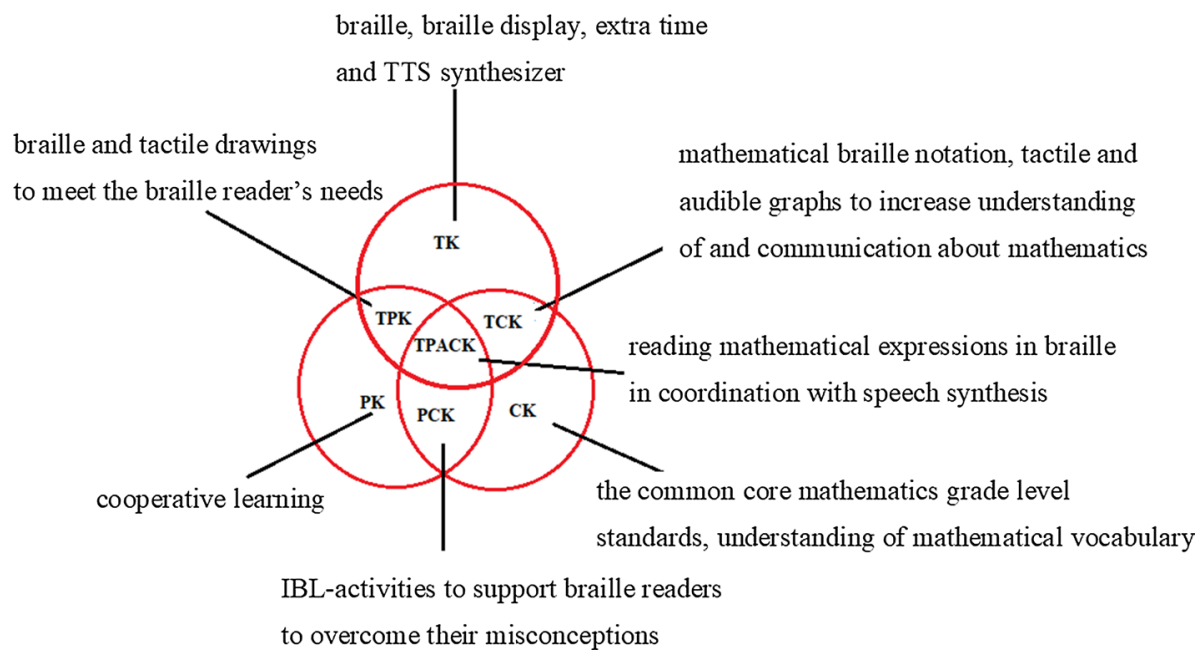

Fig. 3 A TPACK model for mathematics teachers of braille readers

\subsection{Research Questions and Hypotheses}

The following research questions were addressed:

1 How does teachers' TPACK in mathematics for braille readers develop during a foursession PD course?

Although this study has an explorative character, based on previous research (Koehler et al., 2013; Koh et al., 2014) we expect that the teachers will develop their knowledge and skills from believing that the use of assistive devices is the responsibility of the braille readers to understanding that they have a role in the use of these devices. This is one of the results of their better understanding of the intertwinement between technology, mathematical content and pedagogy.

2 Which characteristics of the PD course were beneficial in helping teachers to develop TPACK knowledge and skills, and which characteristics appeared to be less useful?

The course was guided by design principles that characterized the content and the way of working in the PD course. By connecting activities in the course to individual and collective mathematical practices, we expected the teachers to feel the need for a better understanding of how to work and communicate mathematically with assistive devices and how to support braille readers in using these devices. The alternation of modelling new teaching methods with activities during which the teachers can construct or adapt these methods was intended to give them the opportunity to make the new knowledge and skills usable for their practice. Finally, we expected that try-outs and reflective discussions would help them to share positive experiences and to make explicit what works and how to overcome challenges in daily practice. 


\section{Methods}

\subsection{Design of the Study}

To answer the research questions, a PD course was developed focusing on topics that arise from the TPACK model for mathematics teachers of braille readers. A mixed-method approach was taken for investigating the effect of the course on the teachers, using a preand a post-interview an evaluation questionnaire and a logbook to record relevant observations and to contrast these observations with hypothesized learning goals. Results from the pre- and post- interviews and the evaluation questionnaires were used to answer the first research question. To answer the second research question, we analyzed the learning and reported feedback of two case teachers in more detail. In the case reports, we included contextual factors that influenced the TPACK development of the teachers (Koehler et al., 2013; Koh et al., 2014).

\subsection{Participants and Context}

In the Netherlands, there are four secondary schools for students with a visual impairment. More than half of all braille readers in secondary education, from 12 to 18 years, attend one of these four schools. Five mathematics teachers, from two of these schools, volunteered to participate in the PD course. Three of them had less than five years of experience teaching students with visual impairments, while two teachers had more than five years of experience. The teachers did not receive any specific training in teaching mathematics to students with a visual impairment. They were all qualified teachers, but only one was qualified to teach mathematics. About $30 \%$ of their students were braille readers. The other students were visually impaired but did not use braille. The teachers taught in small groups of two to eight students. All students used the same mathematics books, in print or in braille, as students with normal vision (in regular education). The braille readers were taught by a braille teacher how to use the braille display and TTS synthesizer, but not how to use these devices in mathematics. In almost every mathematics lesson, some students used the (formal) mathematical notation, while others used the mathematical braille notation. The latter group of students concerns braille readers who use braille or speech synthesis, as well as print readers who use linear-print expressions.

\subsection{Design of the Professional Development Course}

The topics of the PD course originated from the TPACK model. The intended and hypothesized learning goals were expressed in TPACK goals (see Table 1). The topics in the first two sessions were related to supporting braille readers in reading and comprehending mathematical expressions in braille and speech synthesis. The affordances and constraints of the braille display and the TTS synthesizer were discussed and applied to tasks involving mathematical expressions. We expected that this would support teachers to develop TK, TPK, TCK and TPACK knowledge and skills.

The third session was about working with heterogeneous groups with an emphasis on cooperative learning. The teachers participated in and reflected on IBL-activities. We expected that this would improve their PCK and TPACK knowledge and skills. Figure 4 shows one of the IBL-activities in which the teachers took part. This activity was derived from the PRIMAS (Promoting Inquiry in Mathematics and Science Education across 
Table 1 Design of the PD course

Learning goals Corresponding tasks and activities

Session 1: Supporting braille readers to read and comprehend mathematical expressions on the braille display

1 Knowledge of the problems braille readers

Braille-experience

encounter when reading mathematical expressions and equations on the braille display

2 Knowledge about the braille notation

Instructor provides vignettes on students struggling with mathematics and lets the participants actively connect to their practices and pose possible explanations

Participants make analyses of errors committed by braille readers when simplifying an expression or solving an equation

Homework assignment: Develop a plan for supporting a braille reader, in your own practice, to understand the structure of an expression. Make a short report or video clip of the interaction

Session 2: Supporting braille readers to read and comprehend mathematical expressions on the braille display and with the TTS synthesizer

3 Knowledge about mathematical vocabulary

Instructor helps teachers to use mathematical vocabulary when talking about expressions and equations and explains why this is important

4 Knowledge of and skills in reading mathematical expressions and equations with speech synthesis

Instructor models how to adapt the verbosity settings of the Screen Reader Software

5 Understanding of how the use of braille and speech synthesis complement and reinforce each other while doing mathematics

Discussion, related to the participants' experiences, on the advantages, limitations and challenges of reading in braille or with speech synthesis in mathematics lessons. Instructor models how to use braille in coordination with speech synthesis while reading and comprehending mathematical expressions

Homework assignment: Record your findings with speech synthesis during the next three weeks. Discuss your findings with a braille reader. Write a report of the discussion

Session 3: Working with heterogeneous groups

6 Knowledge about cooperative learning

Information on the importance of inquiry and communication while learning mathematics. Teachers participate in and reflect on IBL-activities

Homework assignment: Support a braille reader with exploring a tactile graph. Write a report of the intervention

Session 4: Sustaining daily practice

7 Knowledge about new perspectives

E.g., 3D printer to create tangible models, different software to create audible graphs

8 Ideas for sustaining daily practices

E.g., possibilities to share practice and experiences in follow-up meetings, Microsoft Teams for online collaboration

9 Evaluation of the PD course

Reflection on and evaluation of the PD course

Europe) Project. The teachers had to decide and explain, in small groups, whether the statement about fractions was always, sometimes or never true.

The last (fourth) session was oriented on sustaining the acquired skills in daily practice. New perspectives were also discussed, such as the 3D printer to make tangible models. 
Fig. 4 Example of an IBLactivity

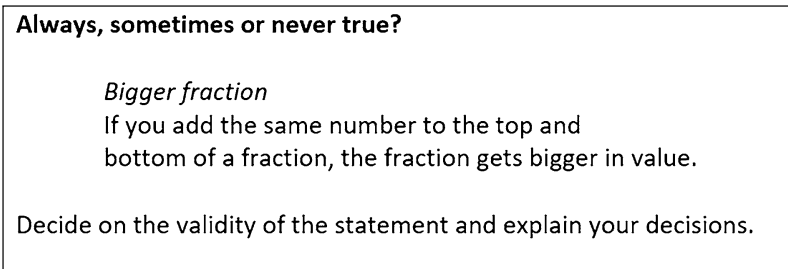

As recommended by Bleicher (2011), we used the last session to stimulate reflection and evaluation of the course. Table 1 provides an overview of the course.

\subsection{Procedure}

The research followed the order of pre-interviews, PD course, evaluation questionnaires and post- interviews, all within four months. The pre- and post-interviews contained the same questions. We investigated whether the participants answered differently in the postinterviews. The course was provided by the first author in four three-hour sessions spread over three months. The pre- and post-interviews were conducted by the course instructor at the participants' schools: once at the start and once at the end of the course. The interviews were scheduled for $40 \mathrm{~min}$, but sometimes took almost an hour. The interviews were recorded and transcribed verbatim. At the end of the course, each teacher completed the evaluation questionnaire. They could take the time to answer the questions. No one needed more than 20 min to complete the evaluation questionnaire.

\subsection{Data Collection Instruments: Interviews and Evaluation Questionnaires}

The data from the interviews and the evaluation questionnaires were used to trace the development of the teachers' understanding of TPACK in mathematics for braille readers. The interviews (see "Appendix 1") were semi-structured with open-ended questions (Whiting, 2008). These questions allow the participants to fully express their viewpoints and opinions (Turner III, 2010). The first question of the interview concerned the pace of reading mathematical expressions by braille readers. The second question was about errors made by braille readers when calculating expressions in braille. The teachers were required to explain the errors. To introduce the third and last question, the teachers were shown a model of three overlapping circles: technology, mathematical content and pedagogy. No other information was given. The teachers were asked to report their perception of confidence in the different domains of this model. The evaluation questionnaire (see "Appendix 2") consisted of five open-ended questions. The questionnaire was developed so that the answers could provide information about the teachers' background, their evaluation of the course, and reported changes in their (TPACK) knowledge and in their attitude. Finally, the course provider's logbook recorded observations and deviations from the original plans for the course. Most notes were made immediately after a PD session. 


\subsection{Development of the Coding Instrument}

The interviews and evaluation questionnaires were coded. The coding is used to segment and reassemble the data and is therefore the most important aid in conducting an analysis (Boeije, 2009). Prior to the actual coding, we began with an "initial list" of potential codes based on the PCK (Shulman, 1986) and TPACK model (Koehler et al., 2013; Mishra \& Koehler, 2006, 2008). This was the start of the codebook. The codes were TK, PK, CK, TCK, PCK, TPK and TPACK. Next, the definitions of these codes were adapted for this particular study. After attempting to code the data utilizing the definitions, we recognized that we could give more explicit definitions. Once we agreed on the definitions, we selected example quotes within the data that best illustrated each code (for codebook, see "Appendix 3").

\subsection{Data Analysis}

In preparation of the coding of the interviews and evaluation questionnaires, we segmented the answers into units of analysis that retained focus on one topic. For example, "They sometimes wear headphones. And then they only use one earpiece, so they can still hear me. At the end of the lesson, those students are exhausted." These units ranged in length from a few words to a couple of lines. The units were coded with one of the TPACK components when they showed proficiency in the related type of knowledge or skill. For example, the unit of analysis just described was coded as PK.

To address the first research question, the interviews and evaluation questionnaires were coded using the codebook. Two interviews and one evaluation questionnaire were also coded by a second coder, resulting in $20 \%$ disagreements. For example, sometimes a teacher indicated very clearly which TPACK knowledge he/she was missing. In that case, one coder wanted to assign a code and the other coder did not. These cases were discussed until consensus was reached. This resulted in keeping the original set of codes, but with improved and better discriminating definitions. For each question, the assigned codes from the pre- and postinterviews were compared on frequency. In addition, we described the nature of the change in codes.

To address the second research question, two cases studies were conducted. B. and W. were selected for these studies because they seem to be at opposite ends of the participating teachers' skills and knowledge spectrum. For the case reports, different sources of data were collected: teachers' interviews, teachers' evaluation questionnaires and the course provider's logbook. For each case study, the data from the case as well as the data from the other teachers were used. The logbook contained information on the conditions of the actual activities (e.g., time available, involvement of participants) and provided context for the responses on the interviews and evaluation questionnaires. We checked consistency by triangulating data from interviews, evaluation questionnaires and observations during the course (see Fig. 5). The case reports were described chronologically, which helped to find causal relationships between the characteristics of the course and the development of the teachers' TPACK knowledge and skills. We analyzed whether the intended learning goals of the course (Table 1) were achieved and which characteristics of the PD course helped to achieve these goals. 


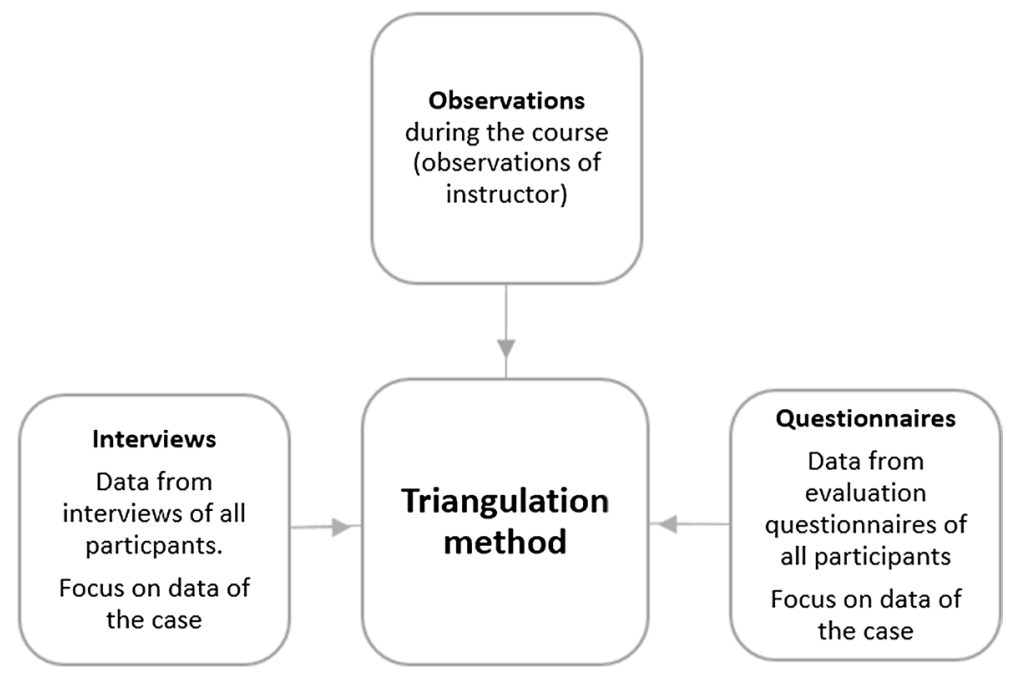

Fig. 5 Triangulation method for the case study

\section{Results}

\subsection{Research Question 1: Teachers'TPACK Development}

\subsubsection{Reading Mathematical Expressions by Braille Readers}

The first research question addresses the teachers' development with respect to their technological, pedagogical and mathematical content knowledge and skills. The first question of the interview, consisting of two sub-questions, was about reading mathematical expressions. In question 1a, teachers had to explain why braille readers need more time to read and understand mathematical expressions and equations than print readers. Teacher W. answered in the post- interview, "They have to build an overview of an expression." This response was assigned the code TPACK.

In question $1 \mathrm{~b}$, the teachers were asked whether they take into account in their classes that braille readers need more time to read and comprehend mathematical expressions and equations. The answers to question $1 \mathrm{~b}$ were almost the same for the pre-interview as for the post- interview. All teachers said that braille readers get all the time they need to complete the mathematical tasks. Teacher T. gave individual instruction. This allowed the braille readers to work at their own pace. Teacher B. gave the braille reader an extra half hour of support every week. All teachers allowed the braille readers to skip assignments if they could show that they had mastered the material sufficiently.

Figure 6a shows the total TPACK scores of the teachers for the first question. In the pre-interview, 25 codes were assigned to the responses to question 1 , and in the post-interview 21 codes. In the pre- interview, the most frequent category was TPACK (13), followed by PCK (7), TCK (4) and PK (1). In the post- interview, the most frequent category was TPACK (14), followed by TCK (3), PCK (2), TCK and TK (both $1)$. The result shows a very small shift from only P-related categories to more T-related categories. 
question 1

Reading mathematical expressions

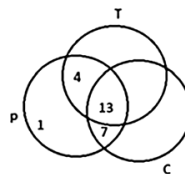

pre-interview

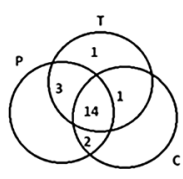

post-interview question 2

Errors in linear expressions

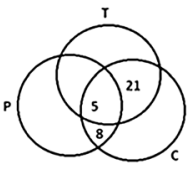

pre-interview

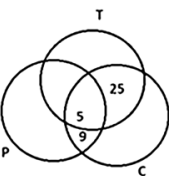

post-interview question 3

Perception of confidence in TPACK

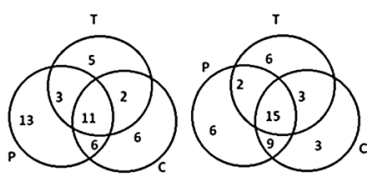

post-interview

Fig. 6 Teachers' total TPACK scores in the pre- and post-interviews in responses to question 1, 2 and 3

\subsubsection{Errors in Calculating Expressions}

The second question of the interview involved errors committed by braille readers while calculating expressions. An illustrative TPACK response on question 2a ("Give a possible explanation for $5-7=-2$ ") was recognizing that the representation of the expression is not according to the rules and unfamiliar for braille readers: "The braille reader doesn't recognize this as a minus sign on the braille display. Therefore, the braille reader calculated five minus seven". (What is meant here is that the screen reader does not recognize the symbol-as a minus sign). In the pre-interviews, all teachers, except for teacher B., said that they shared their own difficulties with the braille notation with their braille readers. One teacher said that it would be fine if the braille readers knew that their teacher also made errors. That would strengthen the bond between teacher and student. Similar comments were made in the post- interviews, but to a much lesser extent.

The results show that 34 codes were assigned to the responses in the pre- interviews, and 39 in the post-interview (Fig. 6b). In the pre- interview, the most frequent category was TCK (21), followed by PCK (8) and TPACK (5). In the post-interview, the most frequent category was TCK (25), followed by PCK (9) and TPACK (5).

\subsubsection{Perception of Confidence in TPACK}

The third question of the interview addresses the teachers' perceptions of confidence in the different domains of TPACK. In the pre- and post- interviews, all teachers mentioned that they felt confident on the P-domain (in isolation). In the post-interviews, all teachers mentioned that they increasingly checked whether the braille readers could read the expressions in braille and corrected them when necessary. In the post- interviews, they also mentioned that they wanted to integrate more assistive devices, such as tactile drawings and tangible models, in their lessons, but they still felt insecure in the area of assistive technology. In the pre-interview, B. said that her mathematical knowledge was "good enough". This response was assigned the code CK. In the post-interview, she said that her mathematical knowledge was not good enough to properly adapt the assignments in the mathematical textbook for the braille readers. Although awareness of one's own limitation of knowledge is relevant for the teacher's learning process, this answer was not assigned a code since no proficiency was shown. Figure $6 c$ shows that 46 codes were assigned to the responses in the pre-interview, and 44 in the post-interview. The most frequent category in the pre-interview was PK (13) followed by TPACK (11), PCK and CK (both 6), TK (5) and TPK (3). The most 
frequent category in the post- interview was TPACK (15), followed by PCK (9), PK and TK (both 6), CK and TCK (both 3) and TPK (2).

\subsubsection{Self-Reported Changes in Working Practice}

Finally, we give the results of the responses on the evaluation questionnaires. These results are not depicted in Fig. 6. Only the responses to the questions that relate to TPACK knowledge and skills were coded (question 3 and 4, see "Appendix 2"). All teachers mentioned that they were more conscious of the problems that braille readers encounter while doing mathematics. However, they felt that they still had a lot to learn in this area and they wanted more support and direction. For example, the teachers wanted more support from the ICT department. The responses to the evaluation questionnaire were assigned the codes TPACK (13), TPK (4), TCK (4) and TK (2).

\subsection{Research Question 2: Characteristics of the PD Course that Support the TPACK Development of the Teachers}

The second research question refers to which characteristics of the course helped to develop TPACK knowledge and skills. To answer this question, two case studies were conducted. The cases were teacher B. and teacher W. Teacher B. had worked at the school for visually impaired students for more than 5 years. She was a qualified primary school teacher. Her class, at the time of the study, consisted of four 7th grade students: one braille reader and three students who were visually impaired but did not use braille. She used a more teacher-centered than student-centered learning approach. She gave the braille reader extra mathematics lessons for half an hour every week. In these lessons, she supported the braille reader, for example, to explore tactile graphs. Thanks to these extra lessons, the braille reader could keep up with his classmates.

B. was responsible for braille education in her school. She could read non-mathematical braille text very well. She had little knowledge about the braille display and the TTS synthesizer. B. mastered the mathematical content she had to teach, but not at a level that exceeded the level of teaching.

Teacher W. has been working at the school for visually impaired students for less than 5 years and taught students from grade 9-11. He was educated as an engineering teacher. He taught at a different school than B. His classes, at the time of the study, consisted of two to five students. There were at most two braille readers in each class. In each mathematics lesson, W. gave instruction to one or two, constantly changing, students. In the meantime, the other students worked independently.

The first session of the PD course was about how to support braille readers with reading and comprehending mathematical expressions in braille. After this session, B. practiced reading mathematical expressions in braille on her own. She used to read expressions aloud to the braille reader to support him to make pace. She realized, due to discussions during the first session of the course, that this would not help him to improve his braille reading. Therefore, over the time of the course she increasingly asked the braille reader to read expressions aloud and corrected him when needed. She was very surprised to find that the braille reader had so many difficulties reading mathematical expressions accurately.

W. knew just a little about braille, the braille display and the TTS synthesizer. In many mathematical braille notations, more brackets are used as grouping symbols than in the (formal) mathematical notation. This is because all characters need to be represented on 
the baseline. Compare, for example, $\frac{4+3}{9-7}$ with $(4+3) /(9-7)$. W. found it difficult to understand the structure of a linear-print expression when it contains many brackets. Thanks to the activities in the course, he was able to overcome these problems. Over the time of the course, W. increasingly asked braille readers to read expressions aloud and corrected them if necessary. In the post- interview, he said that he would like to support braille readers with using the braille display in mathematics but not at this stage of his career. "First, I have to put the other things on track".

In the second session of the PD course, the teachers were taught how to teach braille readers to use speech synthesis while reading and comprehending mathematical expressions. The idea was that braille readers start with using speech synthesis to get an overview of an expression and continue in braille. B. and W. both struggled to understand which symbols in an expression are important to get an overview. In addition, B. feared that teaching braille readers to use braille in coordination with speech synthesis would be detrimental to their motivation to (learn to) read mathematical expressions in braille. About the use of the TTS synthesizer W. said, "Braille readers use the TTS synthesizer themselves. They don't need our support." Furthermore, in this session, the teachers learned to talk about expressions in mathematical vocabulary.

The third session was about "working with heterogeneous groups." The focus was on cooperative learning. This approach was very new to B. and W., and they felt it was not a very effective approach. Moreover, they had difficulties with understanding the underlying mathematics in the IBL activities. In the evaluation questionnaire, they indicated that they wanted more information about teaching heterogeneous groups.

The last session was about supporting daily practice. The teachers discussed setting up a community for mathematics teachers of braille readers. B. and W. were enthusiastic about this idea. At the end of this session, the teachers reflected on the main ideas and theories of the course.

In the evaluation questionnaire, all teachers wrote that they were more aware of the difficulties and challenges that braille readers encounter in mathematics. They all wanted to enroll in the next PD course to learn more about the mathematics education of braille readers. W. wrote, "I realize that I lack knowledge about the mathematical education of braille readers."

\section{Conclusions and Discussion}

\subsection{RQ1: Teachers' TPACK Development}

\subsubsection{Reading Mathematical Expressions by Braille Readers}

In this paper, we set out two questions, the first of which was: How does teachers' TPACK in mathematics for braille readers develop during a four-session PD course? The data from the interviews and evaluation questionnaires were used to answer this question. For interview question 1, that was related to reading mathematical expressions in braille or with speech synthesis, the results show a very small shift from only P-related categories to more T-related categories. The teachers did not change their daily practice in dealing with the fact that braille readers need extra time to read and comprehend mathematical expressions. 
None of the teachers indicated that they encouraged or helped the braille readers to speed up the pace when reading mathematical expressions.

\subsubsection{Errors in Calculating Expressions}

The results with respect to interview question 2 show that the participating teachers improved their knowledge of the braille notation (which is operationalized in an increment of TCK). More specifically, they gained a better understanding of linear-print expressions. However, they did not improve their ability to relate braille readers' errors in calculating expressions to problems with braille reading (which would increment the TPACK-category).

\subsubsection{Perception of Confidence in TPACK}

The results with respect interview question 3 show minimal changes in TPACK codes. In the post- interviews, the teachers focused more on the interaction between the TPACK components, and less on the TK, CK and PK in isolation. However, this did not always result in more assigned codes on the overlapping areas (TPK, TCK, PCK or TPACK). Teacher B. said, for example, that she needs more mathematical knowledge to properly adapt the commands in the braille readers' books. While this was a meaningful comment, no code was assigned to this answer as no proficiency was shown.

\subsubsection{Self-Reported Changes in Working Practice}

The responses for question three and four of the evaluation questionnaire both refer to self-reported changes in the teachers' working practice. The results show a domination of technology-oriented responses.

Overall, the results show an increased awareness that the use of assistive devices influences the teaching and learning of mathematics. The results also illustrate that the teachers feel more responsible for the use of the assistive devices. We assumed, based on research by Koehler et al. (2013) and Koh et al. (2014), a positive relation between teachers' TPACK knowledge and their perception of responsibilities. The results are in line with what we expected, although we hoped for a better result.

\subsection{RQ2: Characteristics of the PD Course that Support the TPACK Development of the Teachers}

As a second research question, we wondered which characteristics of the PD course were beneficial in helping teachers to develop TPACK knowledge and skills, and which characteristics appeared to be less useful. The results show that the teachers did improve their understanding of how the braille display and the mathematical braille notation influence the teaching and learning of mathematics (TCK and TPACK knowledge). They also improved their mathematical vocabulary (CK knowledge). The course activities were closely linked to their practice (design principle 1) (Koehler et al., 2013; Koh et al., 2014). That supported teachers to connect with what they already know and to feel the need to support braille readers. The instructor often acted as a role model (design principle 3) to support teachers in putting what they learned into practice 
(Lunenberg et al., 2007). The teachers were given ample opportunities to discuss with each other (design principle 4) (Van Veen et al., 2010) and reflected on their experiences in follow up meetings (design principle 5) which supported them to share positive experiences and make explicit what works and how to overcome challenges in daily practice. In summary, the activities that were characterized by design principle 1, 3, 4 and 5 were beneficial for improving TPACK knowledge and skills related to the braille display, mathematical braille notation and mathematical vocabulary. This indicates that the learning goals 1, 2 and 3 (see Table 1) were achieved.

The results also show that activities related to the TTS synthesizer and working with heterogeneous groups did not work out well. These activities were guided by the same design principles as the activities just described. However, the teachers did not improve their understanding of how to use speech synthesis while reading and comprehending mathematical expressions (TCK knowledge). Nor did they understand how IBL-activities might resolve misconceptions in mathematics (PCK knowledge). This may be due to the fact that teachers had preconceptions that were different from the views of learning and teaching that we wished to develop. For example, teacher W. remarked. "Braille readers use the TTS synthesizer themselves. They don't need our support." In addition, the teachers felt that cooperative learning is an ineffective approach. Another difficulty was that the teachers did not fully understand the mathematics underlying the IBL-activities. As a result, intended learning goals and underlying activities with respect to the TTS synthesizer and working with heterogeneous groups (see Table 1, learning goal 4,5 and 6) did not emerge.

This study has some limitations. The first is the small number of participants. This offers little basis to generalize the findings. However, we provided detailed descriptions that allow readers to make connections between elements of this study and their own experience. The second limitation concerns the teachers' knowledge of mathematical content and assistive technology. This knowledge was less than we expected. Therefore, the course material was sometimes too difficult for the teachers. Further research into how teachers with lack of mathematical content knowledge and assistive technology can develop their TPACK knowledge and skills_-in mathematics education for braille readers-is needed. The third limitation is related to the role and responsibilities of the teachers. A basic idea behind TPACK is that the teacher is the key to using assistive technology in the classroom. This was something we had to discuss very often on the course, as teachers did not always agree. We did not expect this to be the case to that extent. In future studies, we recommend research to investigate how to support mathematics teachers of braille readers in taking responsibility for the use and selection of assistive devices.

This study shows how the TPACK model can be adapted for mathematics teachers of braille readers. This adaptation guided our choices for the topics in the PD course. The role of tactile and auditory perception in mathematics learning were central in our TPACK model and in the PD course. For example, we addressed the complex interaction between mathematical, technological and pedagogical content knowledge needed to support students in reading a mathematical expression with the braille display. This included knowledge about the selection of assistive devices, their strengths and their shortcomings for learning mathematics (Koehler \& Mishra, 2008). This study also illustrates how the TPACK model can become instrumental in educational contexts that require specific technological devices or sensorimotor coordination.

In addition to theoretical implications, there are also more practical ones. The TPACK model was useful for the design of the PD course. It helped to identify topics on the domains that overlap (e.g., the mathematical braille notation in TCK). The TPACK model also guided us during the analysis, when we mapped the needs and skills of the teachers. 
For example, it helped in recognizing that teachers did develop their knowledge of the mathematical braille notation. However, the teachers did not link the errors in reading and calculating expressions to the complexity of reading in braille. That would have resulted in an improvement in the TPACK domain. The TPACK model shows that assistive devices all have their own potential, features and limitations that make them more appropriate for certain tasks and pedagogies than for others (Koehler \& Mishra, 2008). We created an awareness over the choice of assistive devices and suggested teachers to use braille as well as speech synthesis while reading and comprehending an expression. This study illustrates that the task of the teachers is complex because of all the overlapping areas in TPACK. The PD course provides clues for its significance for practice and for supporting teachers. These suggestions can be used in training both new teachers and in-service teachers.

Finally, a better understanding of what teaching mathematics to braille readers comprises is expected to improve their learning and to afford successful school careers for these students. Our study shows that teaching mathematics to braille readers is not limited to translating instruction materials into braille. It affects all domains of the TPACK model.

\section{Appendix 1}

\section{The Interview Structure}

\section{Question 1: Reading Mathematical Expressions by Braille Readers}

(a) Braille readers need more time to read and comprehend mathematical expressions and equations than students who can see. Can you explain why?

(b) Do you take this into account during your lessons? How?

\section{Question 2: Errors in Calculating Expressions}

The next questions were typed in Word. The braille reader read the questions on the braille display and calculated the expressions. Can you explain the errors he made?
(a) $5--7=-2$
(b) $3 / 5 * 2=3 / 10$
(c) $2^{\wedge} 2+3^{\wedge} 2=10$
(d) $2^{\wedge} 2+3^{\wedge} 2=26$
(e) $1-\operatorname{sqrt}((1+3) /(2+7))=7 / 9$

\section{Question 3: Perception of Confidence in the Different Domains}

Can you say something about your perception of confidence in the different domains of this model?

See Fig. 7. 


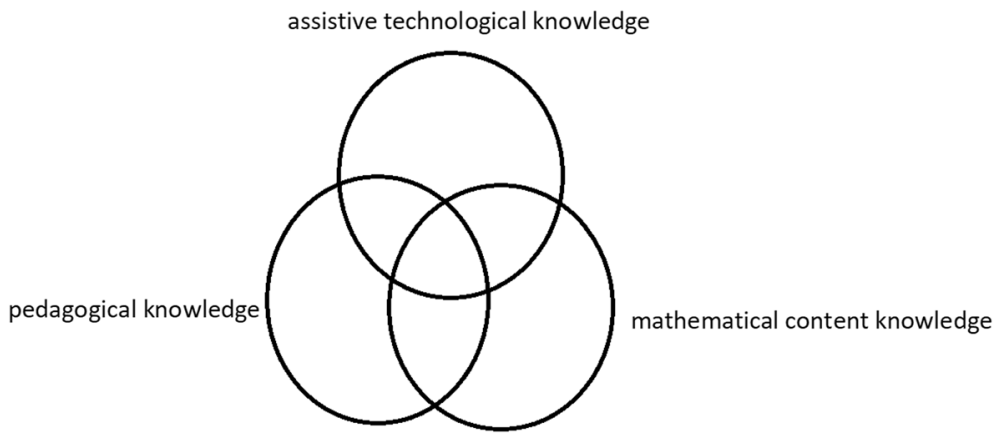

Fig. 7 The interview structure

\section{Appendix 2}

See Fig. 8.

\section{Evaluation Questionnaire}

1. What are your education and work experiences?

2. What kind of work do you do at the school for visually impaired students?

3. Which assignments and / or information from the Professional Development course did you use in your daily practice? Explain.

4. On which topics do you want to deepen your knowledge after the course? Explain.

5. What did you think of the course?

Fig. 8 Evaluation questionnaire

\section{Appendix 3}

See Table 2. 


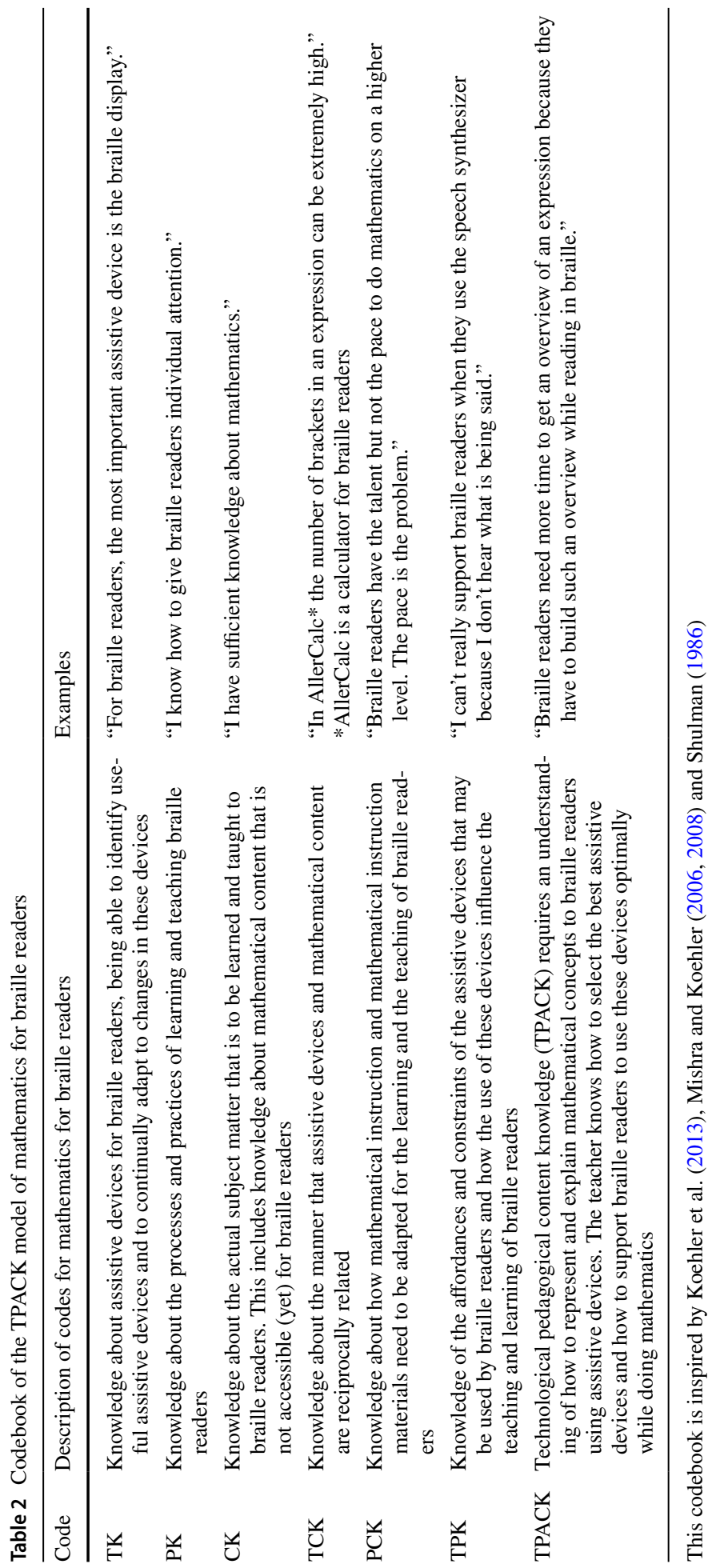


Open Access This article is licensed under a Creative Commons Attribution 4.0 International License, which permits use, sharing, adaptation, distribution and reproduction in any medium or format, as long as you give appropriate credit to the original author(s) and the source, provide a link to the Creative Commons licence, and indicate if changes were made. The images or other third party material in this article are included in the article's Creative Commons licence, unless indicated otherwise in a credit line to the material. If material is not included in the article's Creative Commons licence and your intended use is not permitted by statutory regulation or exceeds the permitted use, you will need to obtain permission directly from the copyright holder. To view a copy of this licence, visit http://creativecommons.org/licenses/by/4.0/.

\section{References}

Adler, J. (2000). Conceptualising resources as a theme for teacher education. Journal of Mathematics Teachers Education, 3, 205-224

Artigue, M., \& Blomhøj, M. (2013). Conceptualizing inquiry-based education in mathematics. ZDM, 45(6), 797-810

Baril, F. (2008). Integration of students with a visual impairment in mainstream vs specialized schools: Advantages and disadvantages. Institut Nazareth \& Louis-Braille.

Bleicher, E. (2011). The last class: Critical thinking, reflection, course effectiveness, and student engagement. Honors in Practice, 7, 39-51

Boeije, H. (2009). Analysis in qualitative research. Sage Publications.

Cox, S., \& Graham, C. R. (2009). Using an elaborated model of the TPACK framework to analyze and depict teacher knowledge. TechTrends, 53(5), 60-69

DePountis, V. M., Pogrund, R. L., Griffin-Shirley, N., \& Lan, W. Y. (2015). Technologies used in the study of advanced mathematics by students who are visually impaired in classrooms: Teachers' perspectives. Journal of Visual Impairment and Blindness, 109(4), 265-278

Drijvers, P., \& Doorman, M. (1996). The graphics calculator in mathematics education. The Journal of Mathematical Behavior, 15(4), 425-440

Drijvers, P., Tacoma, S., Besamusca, A., Doorman, M., \& Boon, P. (2013). Digital resources inviting changes in mid-adopting teachers' practices and orchestrations. ZDM, 45(7), 987-1001

Gadanidis, G., \& Geiger, V. (2010). A social perspective on technology-enhanced mathematical learning: From collaboration to performance. ZDM, 42(1), 91-104

Graham, C. R. (2011). Theoretical considerations for understanding technological pedagogical content knowledge (TPACK). Computers \& Education, 57(3), 1953-1960

Gueudet, G., Pepin, B., \& Trouche, L. (Eds.). (2012). From text to 'lived' resources: Mathematics curriculum materials and teacher development. Springer.

Guskey, T. R. (2002). Professional development and teacher change. Teachers and Teaching: Theory and Practice, 8(3/4), 381-391

Harris, J., Mishra, P., \& Koehler, M. (2009). Teachers' technological pedagogical content knowledge and learning activity types: Curriculum-based technology integration reframed. Journal of Research on Technology in Education, 41(4), 393-416

Hughes, B. (2011). Movement kinematics of the braille-reading finger. Journal of Visual Impairment and Blindness, 105(6), 370-381

Koehler, M. J., \& Mishra, P. (2008). Introducing TPCK. AACTE Committee on Innovation and Technology. The handbook of technological pedagogical content knowledge (TPCK) for educators (pp. 3-29). Mahwah, NJ: Lawrence Erlbaum Associates.

Koehler, M. J., Mishra, P., \& Cain, W. (2013). What is technological pedagogical content knowledge (TPACK)? Journal of Education, 193(3), 13-19

Koh, J. H. L., Chai, C. S., \& Tay, L. Y. (2014). TPACK-in-Action: Unpacking the contextual influences of teachers' construction of technological pedagogical content knowledge (TPACK). Computers and Education, 78, 20-29

Lunenberg, M., Korthagen, F., \& Swennen, A. (2007). The teacher educator as a role model. Teaching and Teacher Education, 23(5), 586-601

Maass, K., \& Doorman, M. (2013). A model for a widespread implementation of inquiry-based learning. ZDM, 45(6), 887-899

Michaels, C. A., \& McDermott, J. (2003). Assistive technology integration in special education teacher preparation: Program coordinators' perceptions of current attainment and importance. Journal of Special Education Technology, 18(3), 29-44 
Millar, S. (1994). Understanding and representing space: Theory and evidence from studies with blind and sighted children. Clarendon Press/Oxford University Press.

Millar, S. (1997). Theory, experiment and practical application in research on visual impairment. European Journal of Psychology of Education, 12(4), 415-430

Mishra, P., \& Koehler, M. J. (2006). Technological pedagogical content knowledge: A framework for teacher knowledge. Teachers College Record, 108(6), 1017

Mishra, P., \& Koehler, M. J. (2008). Introducing technological pedagogical content knowledge. In Annual meeting of the American educational research association (pp. 1-16).

Mumtaz, S. (2000). Factors affecting teachers' use of information and communications technology: a review of the literature. Journal of Information Technology for Teacher Education, 9(3), 319-342

Pierce, R., \& Stacey, K. (2010). Mapping pedagogical opportunities provided by mathematics analysis software. International Journal of Computers for Mathematical Learning, 15(1), 1-20

Pogrund, R., \& Smith, D. W. (2012). A short-term training model on assistive technology: Perceptions of preservice teachers of students with visual impairments. Insight: Research and Practice in Visual Impairment \& Blindness, 5(2), 100-110

Powers, R., \& Blubaugh, W. (2005). Technology in mathematics education: Preparing teachers for the future. Contemporary Issues in Technology and Teacher Education, 5(3), 254-270

Pring, L. (1984). A comparison of the word recognition processes of blind and sighted children. Child Development, 55, 1865-1877

Riccomini, P. J., Smith, G. W., Hughes, E. M., \& Fries, K. M. (2015). The language of mathematics: The importance of teaching and learning mathematical vocabulary. Reading and Writing Quarterly, 31(3), 235-252

Roschelle, J., Shechtman, N., Tatar, D., Hegedus, S., Hopkins, B., Empson, S., Knudsen, J., Lawrence, P., \& Gallagher, L. P. (2010). Integration of technology, curriculum, and professional development for advancing middle school mathematics: Three large-scale studies. American Educational Research Journal, 47(4), 833-878

Shulman, L. S. (1986). Those who understand: Knowledge growth in teaching. Educational Researcher, 15(2), 4-14

Stöger, B., \& Miesenberger, K. (2015). Accessing and dealing with mathematics as a blind individual: State of the art and challenges. In G. Kouroupetroglou (Ed.), Proceedings of international conference on enabling access for persons with visual impairment. (pp. 199-203). Athens: National and Kapodistrian University of Athens Department of Informatics and Telecommunications Speech and Accessibility.

Swan, M., Pead, D., Doorman, M., \& Mooldijk, A. (2013). Designing and using professional development resources for inquiry-based learning. ZDM, 45(7), 945-957

Tobin, M. J., \& Hill, E. W. (2015). Is literacy for blind people under threat? Does braille have a future? British Journal of Visual Impairment, 33(3), 239-250

Turner, D. W., III. (2010). Qualitative interview design: A practical guide for novice investigators. The Qualitative Report, 15(3), 754-760

Van Leendert, A., Doorman, M., Drijvers, P., Pel, J., \& Van der Steen, J. (2019). An exploratory study of reading mathematical expressions by braille readers. Journal of Visual Impairment and Blindness, 113(1), 68-80. https://doi.org/10.1177/0145482X18822024

Van Veen, K. V., Zwart, R. C., \& Meirink, J. (2010). Professionele ontwikkeling van leraren: een reviewstudie naar effectieve kenmerken van professionaliseringsinterventies voor leraren. ICLON / Expertisecentrum Leren van Docenten.

Voogt, J., Fisser, P., Pareja Roblin, N., Tondeur, J., \& Van Braak, J. (2013). Technological pedagogical content knowledge: A review of the literature. Journal of Computer Assisted Learning, 29(2), 109-121

Whiting, L. S. (2008). Semi-structured interviews: guidance for novice researchers. Nursing Standard, 22(23), 35-40

Young, G., \& MacCormack, J. (2018). Assistive technology for students with learning disabilities. Retrieved December 15, 2018 from https://www.ldatschool.ca/assistive-technology/.

Zhou, L., Parker, A. T., Smith, D. W., \& Griffin-Shirley, N. (2011). Assistive technology for students with visual impairments: Challenges and needs in teachers' preparation programs and practice. Journal of Visual Impairment and Blindness, 105(4), 197-210

Publisher's Note Springer Nature remains neutral with regard to jurisdictional claims in published maps and institutional affiliations. 